\title{
Knowing a cross-talk between embryo and endometrium can help to achieve successful pregnancy outcome in recurrent implantation failure
}

\author{
Namrata V. Padvi*, Pooja P. Singh, Purnima K. Nadkarni, Aditi A. Nadkarni
}

Department of Reproductive Medicine and infertility, Nadkarni’s 21st Century Hospital and Test Tube Baby Centre, Surat, Gujarat, India

Received: 21 November 2016

Accepted: 13 December 2016

\section{*Correspondence:}

Dr. Namrata V. Padvi,

E-mail: nams25padvi@gmail.com

Copyright: ( ) the author(s), publisher and licensee Medip Academy. This is an open-access article distributed under the terms of the Creative Commons Attribution Non-Commercial License, which permits unrestricted non-commercial use, distribution, and reproduction in any medium, provided the original work is properly cited.

\begin{abstract}
Recurrent implantation failure is most distressing condition to both couple as well as doctor in the field of reproductive medicine. Patients have already undergone various ART treatments with no favourable outcome and are drained emotionally as well as economically. To overcome this obstacle a comprehensive approach is needed. In this case report, we are addressing a couple who came to us with primary infertility of 15 yrs, with recurrent IVF failures (four cycles of IUI, seven cycles of ICSI both fresh and frozen and with ovum donation in last two cycle), with poor ovarian reserve and male factor infertility for surrogacy as a last option. After complete evaluation of couple, recurrent Implantation failure is thought to be due to poor endometrium and bad embryo quality, and we counselled couple to go for ovum donation and ICSI before considering surrogacy. To improve endometrial receptivity we performed local endometrial injury, oral estradiol therapy, intrauterine G-CSF instillation and IVIG etc. Simultaneously for better quality of embryo we decided to choose ovum donation due to poor ovarian reserve and advance age of the patient and ICSI was done with husband sperm after treatment of male factor infertility and ET was performed. Patient conceived in first cycle with single live intrauterine pregnancy, her antenatal course was uneventful and delivered a healthy baby at term without any complication.
\end{abstract}

Keywords: Embryo, Hysteroscopy, Implantation, ICSI, IVF, Oocyte, Recurrent implantation failure

\section{INTRODUCTION}

Recurrent Implantation Failure is defined as failure to achieve a clinical pregnancy after transfer of at least four good-quality embryos in a minimum of three fresh or frozen cycles in a woman under the age of 40 year. ${ }^{1}$ Or when there is failure of IVF after cumulative transfer of more than 10 embryos of high quality. ${ }^{2}$

Pregnancy rate following one cycle of IVF can be as high as $60 \%$. But even in very successful centre, some couples fail repeatedly. The incidence of recurrent implantation failure is $10 \% .{ }^{1}$ Of all couple undergoing IVF/ICSI, only $29 \%$ attain delivery per oocyte retrieval. ${ }^{3}$ Human implantation is complex process and involves embryouterine interactions which are classified in to three stages as apposition, adhesion, and penetration. For successful implantation a "cross talk" between competent embryo and receptive endometrium is mandatory. ${ }^{4}$

In this case report we are addressing couple with primary infertility with recurrent implantation failure with low ovarian reserve and male factor infertility to achieve successful pregnancy with comprehensive approach, in which we prepared endometrium by performing local endometrial injury, intrauterine G-CSF before embryo transfer and subcutaneous injection of G-CSF after embryo transfer, intravenous immunoglobulin. Idiopathic oligospermia was treated with antioxidants simultaneously. Finally ovum donation and ICSI was performed with husband sperm and good quality embryos were transferred. 


\section{CASE REPORT}

A 42 year old patient came to outpatient department with history of primary infertility, recurrent IVF failure, low ovarian reserve along with male factor infertility. Husband age was 45 year old and married since 15 yrs. Since last 10 years they were taking treatment for infertility from various centres and then referred at us for surrogacy as last option. Patient had already undergone various ART work up including ERA test (Figure 1) suggestive of non-receptive endometrium which is probably the cause of recurrent implantation failure. She also had undergone four cycles of IUI, seven cycles of ICSI both fresh and frozen and with ovum donation in last two cycle, and still did not conceive.

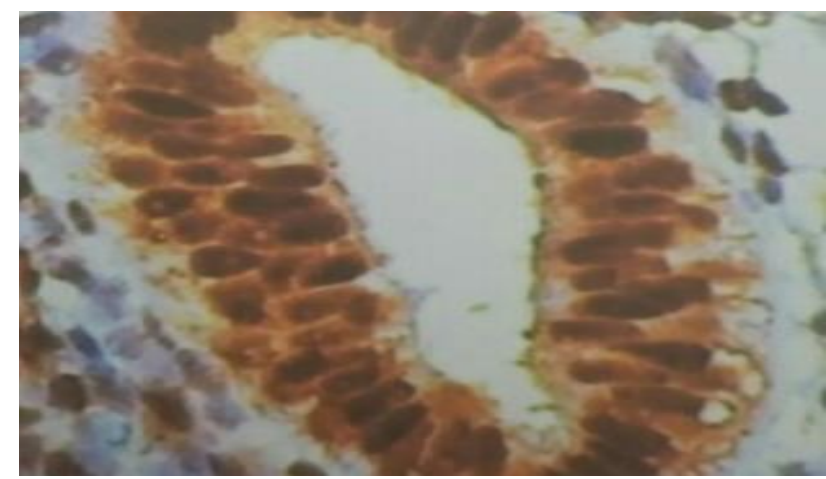

Figure 1A: Era test; p27 positive in $100 \%$ gland nuclei.

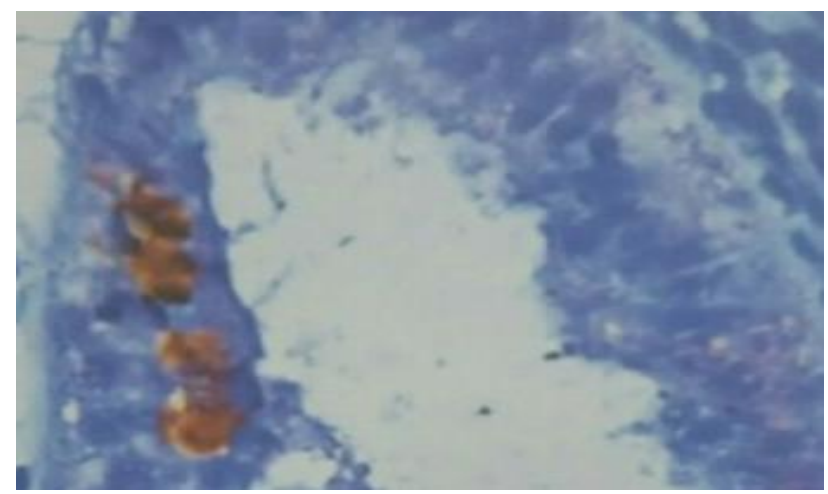

Figure 1B: Era test cyclin $\mathbf{E}$ (positive in $20 \%$ gland nuclei).

At our centre couple was examined thoroughly with complete history, physical examination, menstrual and past treatment history in detail. In menstrual history patient had regular menses, internal examination did not reveal any significant finding, patient was obese with BMI of 35, with no significant medical or surgical illness.

Husband was also evaluated in our andrology opd for male factor infertility, nothing significant was found in physical examination, but semen analysis report showed idiopathic oligo-astheno-terato-zoospermia (4 million count, $30 \%$ motility), with normal DNA fragmentation test and karyotype. Patients all basic investigation was done including all hormonal profile, thyroid profile, thrombophilia profile, karyotype all were normal. Her AMH was $0.2 \mathrm{ng} / \mathrm{ml}$ and antral follicle count of 3 , suggestive of poor ovarian reserve. On transvaginal ultrasonography her endometrium was thin $6.4 \mathrm{~mm}$ on day 9 .

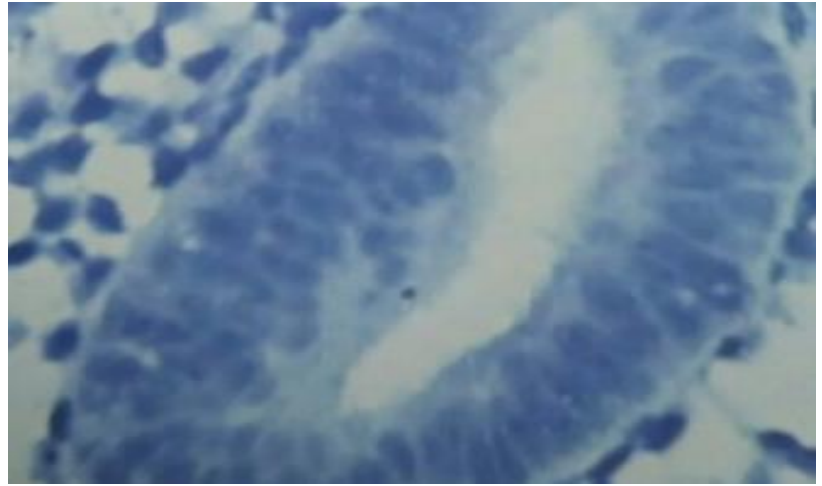

Figure 1C: Era test; Integrin's (Negative).

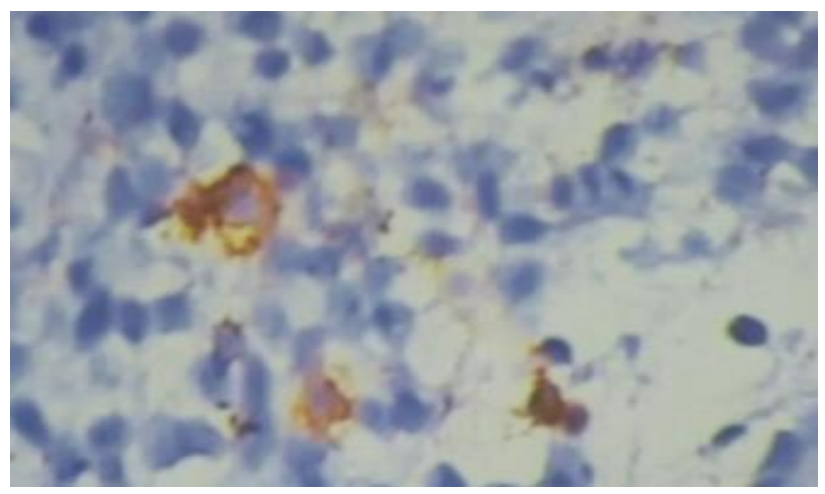

Figure 1D: Era test; natural killer cells activity (moderately positive).

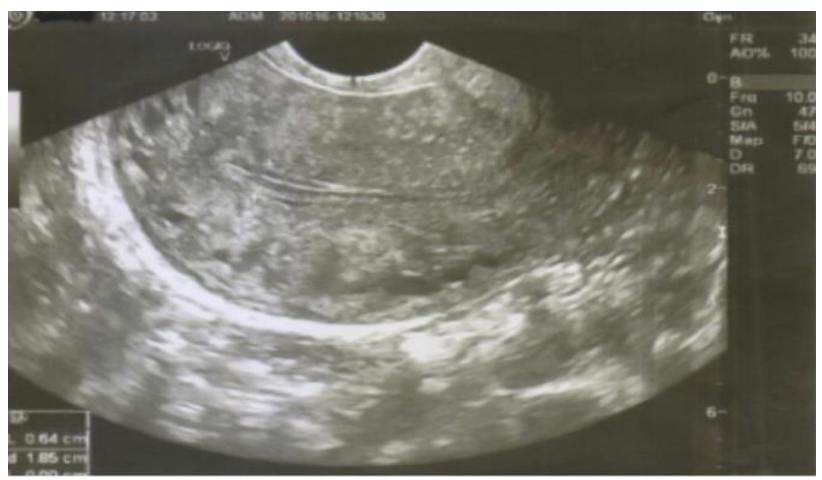

Figure 2: Thin endometrium before G-CSF.

After taking into account of her previous history of seven failed IVF cycle and ERA test report, (which showed the presence of moderate natural killer cell activity. The examination also showed abnormal Cylin E and normal p27. However, the adhesion molecules Integrin are required for blastocyst implantation were absent.) We 
counselled the couple and informed them about different treatment modalities we have, to improve her endometrium and given the option of ovum donation and ICSI for which they consented.

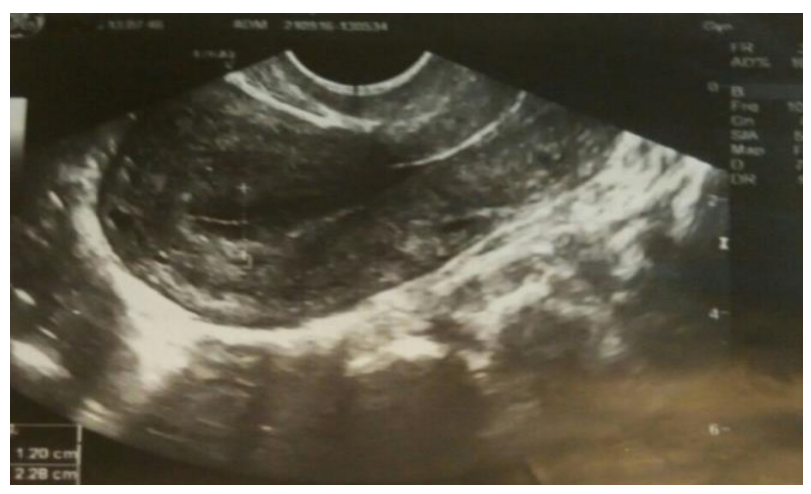

Figure 3: Triple line endometrium after intrauterine G-CSF.

Initially to prepared her endometrium, we did pre IVF hysteroscopy for local endometrial injury, then we started her on estrogen $6 \mathrm{mg}$ daily followed by intrauterine instillation of G-CSF. Serial monitoring of endometrial thickness was done. Husband was treated simultaneously with antioxidants to improve count and motility. Total 9 thawed oocytes were allotted and ICSI done with husband sperm on (5 million with $55 \%$ motility), out of which 6 fertilised, cleaved-6, inj IVIG was given before transfer.

On the day of transfer endometrial thickness was $12 \mathrm{~mm}$ then two grade 1 embryo were transfer on day 2, four embryos kept for blastocyst out of which only one progressed and transferred on day 5. We routinely do sequential transfer in recurrent implantation failure at our centre. Inj G-CSF given subcutaneously after embryo transfer, patient was also started on progesterone, estrogen gel, L -arginine, sildenafil vaginal tablet, aspirin, and steroid and well heparinised after ET. After 15 days her first b-hCG report came to be positive about $1261.11 \mathrm{mIU} / \mathrm{ml}$, and second b-hCG came 6838.02 $\mathrm{mIU} / \mathrm{ml}$. Her first scan confirmed single live intrauterine pregnancy.

\section{DISCUSSION}

We know that the occurrence of recurrent implantation failure is complex process and involves embryo and endometrium. Conditions originated from the endometrial environment, such as uterine anomaly, non-receptive endometrium, maternal autoimmune diseases and abnormal thrombophilia profile can adversely affect the "cross-talk" between the embryo and the endometrium that is crucial for successful implantation.

Similarly, interaction between this endometrium and embryo may be affected if the embryo quality is compromised. Embryo abnormality can originated from both parent. Accordingly, the investigation and treatment of patient with recurrent implantation failure should include both husband and wife. All risk factors should be identified, managed and treated appropriately.

As far as our case is concern, after complete evaluation the reason for recurrent implantation failure is thought to be due to poor endometrium, and poor quality of embryos as result of advance maternal as well as paternal age. So we focused on improving endometrial receptivity, as well as quality of embryo by various means which were acceptable and affordable to our patient.

To begin with patient was posted for diagnostic hysteroscopy; an local endometrial injury was done. Various studies have already shown the significant result of local endometrial injury by means of endometrial scratching/sampling or hysteroscopy. Narvekar et al. has demonstrated that the live birth rates, clinical pregnancy and implantation rates significantly increased after endometrial scraping in the preceding cycle in patients with good-quality embryos. ${ }^{5}$ The exact mechanism for such effect is not fully understood. However, it is postulated that biopsy/scratching induces an inflammatory response that elevated proinflamatory cytokines, as well as increased MIP-1B expression in the regenerative endometrium, this could play a significant role in implantation process.

To further improve endometrium we started her on oral estradiol valerate $6 \mathrm{mg}$ daily, as estrogen supplementation in luteal phase has also shown immense success in patient with recurrent implantation failure due to thin unresponsive endometrium. ${ }^{6}$ Furthermore G-CSF a cytokine/growth factor was instilled intrauterine, as various studies have proven its role in recurrent implantation failure. Gleicher et al. in his prospective study has already demonstrated successful pregnancy outcome after intrauterine instillation of G-CSF in patients undergoing IVF with thin endometrium and concluded G-CSF as wonderful drug to overcome nonreceptive and thin endometrium. ${ }^{7}$

Immunological factors have been implicated in pathogenesis of recurrent implantation failure for long time and different immunomodulator have been use for treatment purpose. So we decided to give IVIG to the patient. Studies have concluded that immunotherapy with IVIG when applied in patients with abnormal immunological risk factors might increase the live birth. ${ }^{8}$

As far as the quality of embryo is concern male counterpart is utmost important. We evaluated the patient for male factor infertility, though sperm count was low, his hormonal profile was normal including sperm DNA fragmentation test and karyotype. We treated him with antioxidants to improve his count. ${ }^{9}$

After all this work up, ovum donation and ICSI with husband sperm was done and two grade 1 embryo were 
transferred on day 2, and one blastocyst transferred on day 5.On the day of transfer endometrium was $12 \mathrm{~mm}$. Inj G-CSF given subcutaneously after embryo transfer, patient was also started on progesterone, aspirin, and steroid and well heparinised after ET.

After 15 days her first b-hCG report came to be positive. Her first scan confirmed single live intrauterine pregnancy. Her antenatal course was uneventful. Patient delivered a healthy baby at term.

\section{CONCLUSION}

Our case of recurrent implantation failure with previous 7 failed cycle was tricky to treat but improving quality of embryo by ovum donation from young fertile donor and improving endometrial receptivity by various means like local endometrial injury, IVIG, G-CSF, improving endometrial blood flow by giving L-arginine, estrogen gel, aspirin, vaginal sildenafil, low molecular weight heparin helped us to achieve successful pregnancy outcome. So we conclude that although managing recurrent implantation failure is difficult, but knowing a cross talk between endometrium and embryo and treating it with the appropriate modalities available and affordable to patient, one may successfully give aggrieved patient her own baby from her own womb.

Funding: No funding sources Conflict of interest: None declared Ethical approval: Not required

\section{REFERENCES}

1. Coughlan C, Ledger W, Wang Q, Liu F, Demirol A, Gurgan $\mathrm{T}$, et al. Recurrent implantation failure: definition and management. Reprod Biomed Online. 2014;28(1):14-38.
2. Shufaro Y, Schenker JG. Implantation failure, etiology, diagnosis and treatment. Int J Infertil Fetal Med. 2011;2:1-7.

3. Andersen AN, Gianaroli L, Felberbaum R, de Mouzon J, Nygren KG. Assisted reproductive technology in Europe, 2001. Results generated from European registers by ESHRE. Hum Reprod. 2005;20:1158-76.

4. Achache h, revel a. Endometrial receptivity markers, the journey to successful embryo implantation. Hum Reprod Updat. 2006;12:731-46.

5. Narvekar SA, Gupta N, Shetty N, Kottur A, Srinivas M, Rao KA. Does local endometrial injury in the nontransfer cycle improve the IVF-ET outcome in the subsequent cycle in patients with previous unsuccessful IVF? A randomized controlled pilot study. J Hum Reprod Sci. 2010;3(1):15-9.

6. Kumar P, Mahajan S. Preimplantation and postimplantation therapy for the treatment of reproductive failure. J Hum Reprod Sci. 2013;6:8892.

7. Gleicher N, Vidali A, Barad DH. Successful treatment of unresponsive thin endometrium. Fertil Steril. 2011;95(2123):e13-7.

8. Coulam CB, Acacio B. Does immunotherapy for treatment of reproductive failure enhance live births? Am J Reprod Immunol. 2012;67(4):296-304.

9. Ghanem H, Shaeer O, El-Segini A. Combination clomiphene citrate and antioxidant therapy for idiopathic male infertility: a randomized controlled trial. Fertil Steril. 2010;93(7):2232-5.

Cite this article as: Padvi NV, Singh PP, Nadkarni PK, Nadkarni AA. Knowing a cross-talk between embryo and endometrium can help to achieve successful pregnancy outcome in recurrent implantation failure. Int J Reprod Contracept Obstet Gynecol 2017;6:739-42. 